\title{
Commentary
}

\section{Maternal immunization: A call to accelerate progress}

Azucena Bardaja ${ }^{\mathrm{a}, *}$

azucena.bardaji@isglobal.org

Noni E. MacDonald

Saad B. Omer

Teresa Aguado $^{\mathrm{a}}$

a ISGlobal, Hospital Clínic - Universityat de- -f Barcelona, Barcelona, Spain

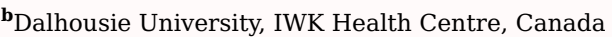

'Emory University, School of Public Health and Medicine. Emory Vaccine Center, Atlanta, GA, USA

${ }^{*}$ Corresponding author at: ISGlobal, Hospital Clínic - Universityat de-of Barcelona, Rosselló, 132. 5-1, 08036 Barcelona, Spain.

\section{Abstract}

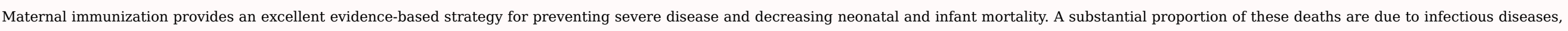
most of them vaccine-preventable, then $n_{\perp}$ there is a real opportunity for intervention.

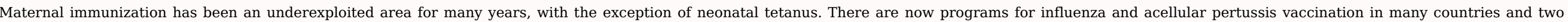

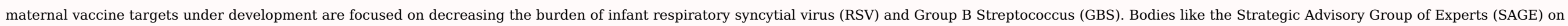

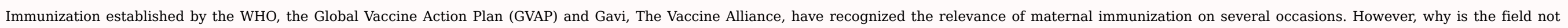
moving faster, as one might expect?

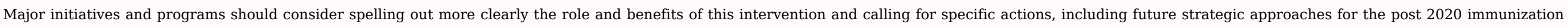

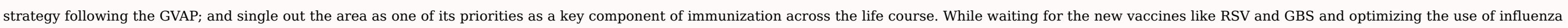
and pertussis there is momentum now to coordinate efforts, address the missing information and action gaps, and call to accelerate progress

Keywords: Maternal; Immunization; Call; Action

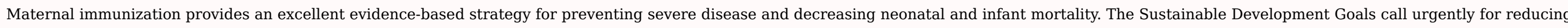

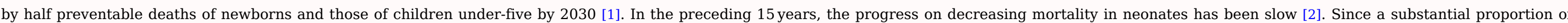
these deaths are due to infectious diseases, most of them vaccine-preventable, there is a real opportunity for intervention.

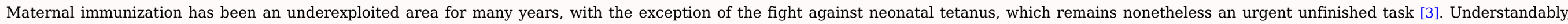

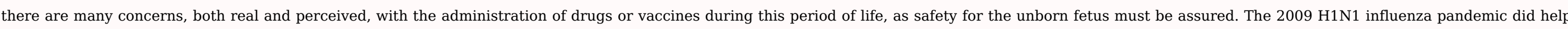
remove barriers, including the perception of higher risk than benefit, for administration of vaccines like influenza in pregnancy given the gains for both mothers and neonates.

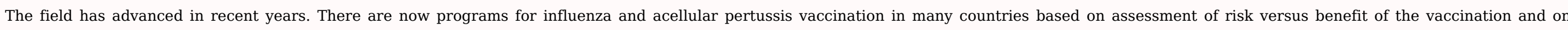

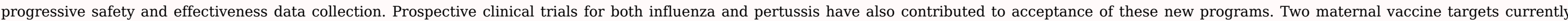




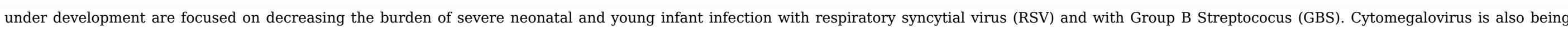

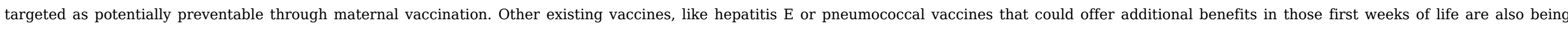
explored.

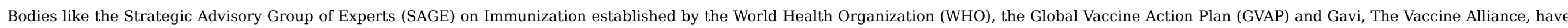

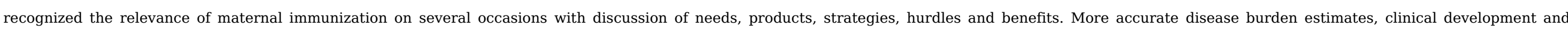

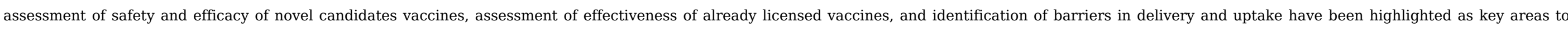
concentrate efforts $[4,5]$.

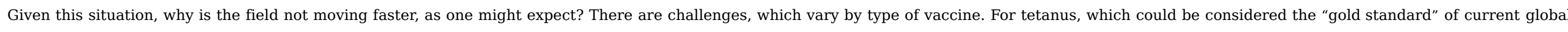

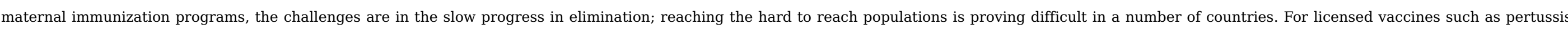

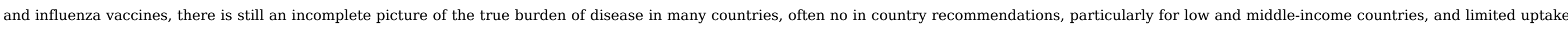

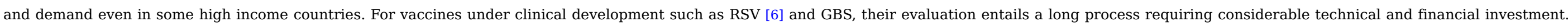

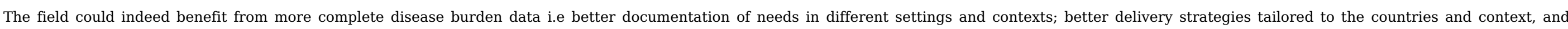

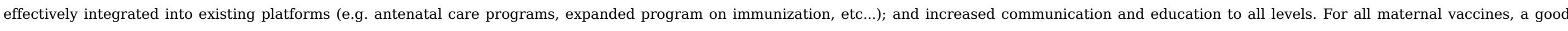
linkage will need to be established between vaccine programs, maternal and infant health experts, and the overall health system at the global and country levels in order to optimize delivery.

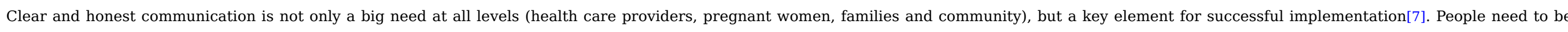

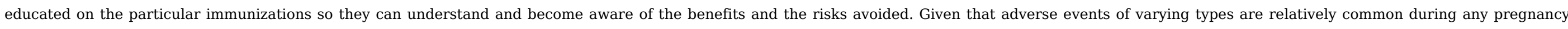

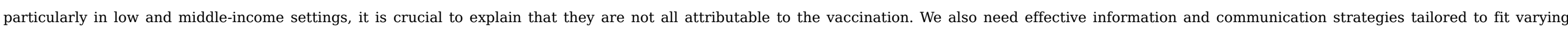

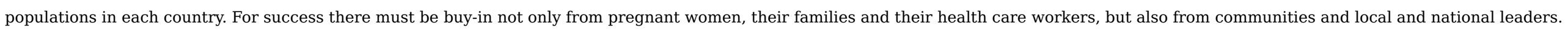

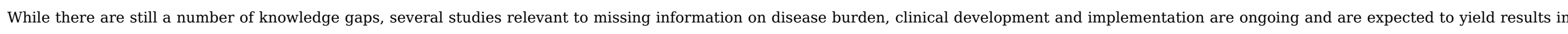

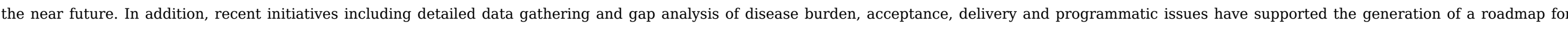

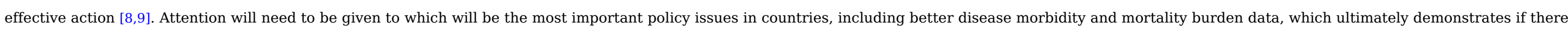
is a problem and how it fares as compared to other health interventions and priorities. Cost effectiveness studies should also contribute to support these decisions.

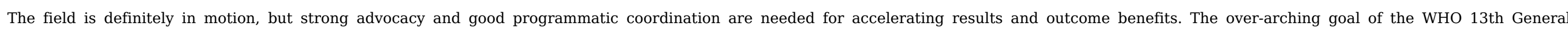

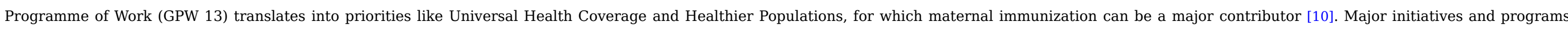

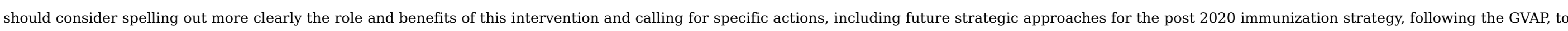
single out the area as one of its priorities as a key component of immunization across the life course.

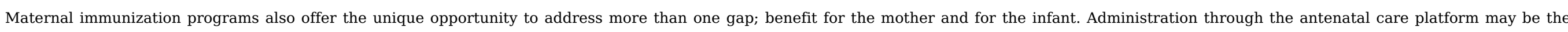

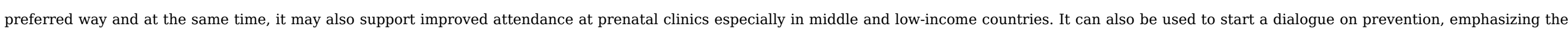

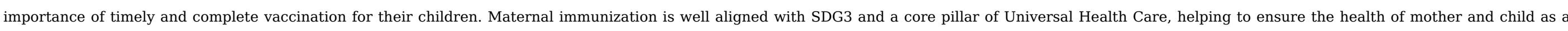

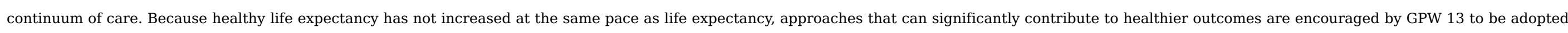
by all countries [10].

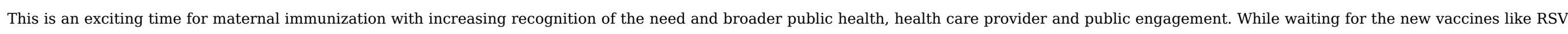
and GBS and optimizing the use of influenza and pertussis there is momentum now to coordinate efforts, address the missing information and action gaps, and call to accelerate progress.

The authors declare that they have no known competing financial interests or personal relationships that could have appeared to influence the work reported in this paper.

This commentary did not receive any source of funding. 


\section{References}

[1] UN, Sustainable Development Goal 3. https://sustainabledevelopment.un.org/sdg3 [accessed Jan 23, 2019].

[2] UNICEF, Levels \& trends in child mortality; 2015. http://www.childmortality.org/files_v20/download/igmereport2015childmortalityfinal.pdf [accessed Jan 23, 2019]

[3] C. Burgess, et al., Eliminating maternal and neonatal tetanus and closing the immunity gap, Lancet 389 (10077), 2017, $1380-1381$.

[4] Weekly epidemiological record. Worl Health Organization. 27 May 2016, 91th Year. No. 21, 2016, 91, 265-84.

[5] Weekly epidemiological record. World Health Organization. 28 Aug 2015, 90th Year. No. 90, 2012, 87, 433-60.

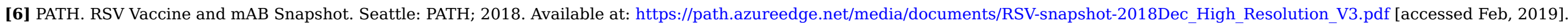

[7] S.B. Omer, Maternal Immunization, N Engl J Med 376 (13), 2017, 1256-1267.

[8] PATH. Advancing RSV Maternal Immunization: a Gap Analysis Report. Seattle: PATH; 2018.

[9] PATH. A Roadmap for Advancing RSV Maternal Immunization. Seattle: PATH; 2018.

[10] WHO Thirteenth General Programme of Work 2019-2023, http://apps.who.int/gb/ebwha/pdf_files/WHA71/A71_4-en.pdf?ua=1.

\section{Queries and Answers}

Query: The author names have been tagged as given names and surnames (surnames are highlighted in teal color). Please confirm if they have been identified correctly. Answer: Yes 